\title{
ORIENTALISME, PERBUDAKAN, DAN RESISTENSI PRIBUMI TERHADAP KOLONIAL DALAM NOVEL-NOVEL TERBITAN BALAI PUSTAKA
}

\author{
I Nyoman Yasa \\ Jurusan Pendidikan Bahasa dan Sastra Indonesia \\ Fakultas Bahasa dan Seni \\ Universitas Pendidikan Ganesha
}

\begin{abstract}
Abstrak
Penelitian yang dilakukan berdasar pada masalah budak dan perbudakan di Indonesia dalam karya sastra dan dilakukan dengan menggunakan teknik dekonstruksi ini memiliki tujuan untuk mendeskripsikan (1) orientalisme dalam novel-novel Balai Pustaka dan (2) resistensi pribumi terhadap kolonial Belanda novel-novel Balai Pustaka.

Hasil penelitian ini menunjukkan bahwa relasi antara penjajah dengan terjajah, yakni antara Belanda dengan pribumi di Indonesia (Hindia Belanda) adalah relasi yang tidak setara. Belanda mendominasi pribumi. Pendominasian Belanda terhadap pribumi diperlihatkan stereotip-stereotip kebinatangan oleh pihak Belanda kepada pribumi, dan pendiskriminasian warna kulit oleh kolonial. Belanda memandang dirinya lebih beradab daripada pribumi karena Belanda memiliki warna kulit putih, sedangkan pribumi memiliki kulit hitam, atau bukan kulit putih. Pandangan Belanda itu terkonstruksi dalam pikiran dan perilaku mereka sehingga stereotip-stereotip bahwa pribumi itu terbelakang, lamban atau malas, dan seperti binatang (kera atau beruk), muncul atau berkembang. Hal itu merupakan pandangan orientalisme colonial Belanda terhadap pribumi. Akibat pendominasian (pendiskriminasian, rasisme, dan marjinalisasi) ini membuat masyarakat pribumi melakukan resistensi. Resistensi yang dilakukan oleh budak/pribumi dalam bentuk mimikri dan mockery yang memperolok-olok kolonial Belanda dalam upaya meruntuhkan kekuasaannya.
\end{abstract}

Kata-kata Kunci: Orientalisme, Resistensi, Balai Pustaka, Poskolonial

\begin{abstract}
This research is conducted based on the problem of slavery found in Indonesian literary texts. Using a deconsructive technique, this research intends to show (1) the relations between the colonizer and colonized people found in the Balai Pustaka's novels (2) the resistance of slaves to his masters.

The result of this research shows unequal relations between the colonizer, Dutch, and colonized people, native Indonesian. These unequal relations can be found through Dutch's expression by stereotyping Indonesian as animals, and by referring to their skin color. The Dutch characters in the novel viewed themselves more civilized than those indigenous characters, and this categorization was formulated based on skin colors. This point of view constructed the colonizer's mind and behaviors that impacted to the emergence of negative depictions of native Indonesians as left behind, slow, lazy people, and other animal likes such as monkey. Such negative depictions and domination (discrimination, racism, and marginalization) led Indonesian slaves into resistance in the form of mimicry and mockery by mocking Dutch colonizers.
\end{abstract}

Key words: Orientalism, Resistance, Balai Pustaka, Postcolonial 


\section{PENDAHULUAN}

Balai Pustaka (1908-1942) didirikan oleh kolonial Belanda dalam upaya melakukan kontrol sosial dan politik terhadap bacaanbacaan liar (teks bacaan yang diterbitkan oleh komunitas Tionghoa, Arab, dan Pribumi) di Indonesia. Kontrol sosial dan politik tersebut dilakukan dalam upaya mengeksistensikan dirinya sebagai satusatunya penjajah yang menaklukkan pribumi seuntuhnya. Oleh karena itu, semua bacaan yang diterbitkan ada dalam pengawasan dan sensor kekuasaannya. Herawati (2010: 200) menyatakan bahwa Belanda memanfaatkan karya sastra sebagai media hegemoni dan dominasi terhadap rakyat pribumi. Kolonial Belanda merekrut pegawai-pegawai kontrak untuk mengurus Balai Pustaka. Abdoel Moeis adalah salah satu contohnya. la diupah tinggi sebagai tenaga kerja di Balai Pustaka. Begitu pun, Sutan Takdir Alisyahbana (Faruk, 2007: 50). Kontrol sosial dan politik yang dilakukan, bukan saja kepada pribumi sebagai tenaga kerja, tetapi juga pengarang (sastrawan) sekaligus karya sastra yang diterbitkan ketika itu.

Novel Salah Asuhan, Siti Nurbaya, dan Belenggu adalah karya sastra-karya sastra yang sudah mengalami sensor dari tangan kolonial sebelum akhirnya teks-teks (novelnovel) itu dibaca masyarakat pribumi. Novelnovel itu harus sesuai dengan standar bacaan yang sudah ditetapkan oleh Balai Pustaka berdasarkan keputusan D.A. Ringkes; salah satunya

adalah karya sastra yang diterbitkan tidak bertentangan dengan garis politik pemerintah Belanda (Sarwadi, 2004: 28). Dalam sensor yang dilakukan, kolonial menciptakan sebuah pencitraan diri, orientalisme, dan tetap menempatkan pribumi sebagai budak. Budak pekerja dan budak peniru budaya-budaya Barat. Walaupun demikian, novel-novel Balai Pustaka juga menunjukkan perlawanann secara tersembunyi dari para pengarang. Darma (2010, 172) menyatakan bahwa dalam karya sastra, dikotomi antara penindas dan tertindas tidak selamanya eksplisit. Novel Azab dan Sengsara misalnya. Mahayana (1994: 18-19) menyatakan Azab dann Sengsara menunjukkan perlawanan dari pribumi.

Orientalisme, perbudakan, dan perlawanan masyarakat pribumi dalam karya sastra terbitan Balai Pustaka tidak lepas dari akumulasi kegelisahan, penderitaan yang dialami masyarakat pribumi semenjak kedatangan Belanda ke Indonesia. Peristiwa-peristiwa sosial budaya ataupun peristiwa sejarah yang terjadi dan berkembang dalam masyrakat direkam berdasarkan sensitivitas sastrawan (Yasa, 2010: 51) dan kemudian ditransformasi ke dalam karya sastra, termasuk semenjak kedatangan Belanda ke Indonesia termasuk politik kolonialnya (Ronidin, 2010: 152).

Sejak awal abad ke-16, kekayaan yang terdapat di kepulauan nusantara menarik bangsa asing untuk datang ke Indonesia (Hindia Belanda) dalam upaya memperbaiki perekonomian mereka ${ }^{1}$.Perdagangan hasil bumi, terutama rempah-rempah, memberikan keuntungan besar bagi Eropa. Keuntungan yang besar itu secara berkelanjutan mengundang bangsa-bangsa Eropa datang ke Indonesia dan berlombalomba menjalankan monopoli perdagangan. Dalam persaingan dagang itu, Belanda sebagai pihak pemenang melalui suatu persekutuan usaha dagang yang disebut VOC (Verenigde Oost Indische Compagnie/Perserikatan Maskapai Hindia Timur) pada awal abad ke-17 atau tepatnya pada tahun 1602 (Ricklefs, 1988: 25; Lasang, 1984: 6). Selanjutnya, Belanda mulai memikirkan mengenai upaya-upaya untuk menguasai perdagangan di tanah air dalam upaya memperkaya negaranya.

Dalam upaya memperkaya negaranya, selain mengeksploitasi kekayaan alam dan

${ }^{1}$ Upaya meningkatkan perekonomian sebagai salah satu alasan utama imperialisme negara negara Barat, selain alasan kompetisi antarnegara (Scholten, 1993: 93) 
melakukan monopoli ${ }^{2}$ perdagangan, Belanda juga melakukan eksploitasi tenaga rakyat melalui perekrutan tenaga kerja budak. Sebagai kaum budak, pribumi dikuasai sepenuh tubuh dan pelayanannya, didudukkan sebagai kelas sosial yang paling rendah, diwajibkan melaksanakan segala perintah penguasa (Nieboer, 1910: 4-5). Berkenaan dengan perekrutan budak itu, akhirnya Indonesia menjadi negeri perdagangan budak (Wertheim, 1999: 186) di berbagai kawasannya. Beberapa kawasan penting di Indonesia yang pernah terlibat praktik perbudakan, antara lain Sulawesi, Jawa, Buton, Irian, Bali, dan Sumatera (Marsden, 1999: 165). Pada masa itu, perbudakan menjadi suatu yang lumrah bagi penduduk di nusantara, khususnya Sumatera. Sementara itu, Pulau Nias dijadikan sebagai daerah penyuplai budak.

Pribumi semakin menderita karena Belanda secara terus-menerus melakukan penindasan dalam beragam macam bentuk. Stratifikasi sosial ${ }^{3}$ yang mengarah pada ra-

\footnotetext{
${ }^{2}$ Perkembangan yang mendorong kapitalisme modern (monopoli) di Indonesia menurut Boejoeng Saleh (dalam Razif, 2005: 13-14) adalah ketika negara kolonial memberlakukan Undang-undang De Waal pada 9 April 1870 yang diperkuat dengan UU Pertambangan 28 Mei 1899 (Minyak, Timah, Batu Bara, Emas, dll). Undang-undang pertama, mencoba menghapuskan Domienverklaring (kekuasaan kolonial yang memanfaatkan penguasa-penguasa pribumi untuk melakukan represi politik ke bawah sehingga Gubernur Jenderal dapat menaklukkan Jawa dan Luar Jawa hanya dengan secarik kertas) yang telah member dasar kapitalisme dengan cara mengobral tanah murah dan menekan upah serendah mungkin; Undang-undang kedua, memperkuat kemungkinan-kemungkinan berkembangnya kapitalisme di Hindia Belanda yang mengundang investasi modal dari negeri lain
}

\footnotetext{
${ }^{3}$ Penggolongan rakyat berdasarkan ras menempatkan orang Eropa Totok dan Indo sebagai penduduk kelas satu, disusul Cina dan Arab sebagai penduduk kelas dua (pada masa VOC terjalin hubungan yang erat antara orang Cina dan Arab dengan kompeni di Batavia. Kepentingan kompeni terhadap orang Cina
}

sisme sengaja diciptakan dalam upaya memecah belah masyarakat pribumi (Casaire dalam Prasaja (1998:1).

Penggambaran mengenai penindasan budak dan perlawanan budak (pribumi) digambarkan dalam karya sastra Siti Nurbaya karya Marah Rusli, Salah Asuhan, Pertemuan Jodoh karya Abdoel Moeis, Hulubalang Raja, dan Katak Hendak Jadi Lembu karya Nur Sutan Iskandar, yang merupakan subjek penelitian ini.

Ada beberapa alasan pentingnya resistensi budak dalam novel-novel terbitan Balai Pustaka tersebut melalui kajian poskolonialisme dilakukan. Alasan berkenaan dengan posisi dan pentingnya karya sastra dan pengarang. Yang pertama adalah novel Siti Nurbaya. Novel ini dikatakan sebagai puncak-puncak kejayaan Balai Pustaka (Sarwadi, 2004: 33). Novel ini dikarang oleh Marah Rusli. Marah Rusli adalah pengarang penting dalam Balai Pustaka. Pentingnya Marah Rusli karena ia dapat mencipatakan karya sastra yang paling banyak dibaca oleh masyarakat (ibid).

Novel yang keduda adalah novel Salah Asuhan karangan Abdoel Moeis. Novel ini juga dapat dikatakan sebagai puncakpuncak kejayaan Balai Pustaka karena novel ini menyampaikan isi dan menggunakan bahasa yang sangat baik bagi Balai Pustaka. Akibat nilai sastra dan bahasa yang tinggi itulah, Abdoel Moeis juga tercatat sebagai pengarang penting bagi Balai Pustaka ketika itu (Sarwadi, 2004: 33). Yang ketiga adalah novel Pertemuan Jodoh karya Abdoel Moeis yang mengungkap kolonialisme didalamnya. Pengungkapan kolonialisme dan adanya

terutama sekali terletak pada perdagangan sampai suatu ketika mereka dianggap sebagai ancaman dan dibunuh tahun 1740), dan bumi putra sebagai penduduk kelas ketiga. Bumiputra (kaum inlander) dibagi lagi atas kaum priyayi dan rakyat jelata (Cristanty, 1994: 21). Sementara itu, Fasseur (1994:32) juga menyampaikan bahwa sepanjang abad ke-17 dan ke-18, agama menjadi kiteria dalam mengklasifikasikan masyarakat di bawah kekuasaan kaum gereja hingga pada aturan hukumhukum pengadilannya. 
ideologi kolonialisme dalam novel Salah Asuhan juga menjadikan pertimbangan novel Pertemuan Jodoh sebagai novel yang dikarang oleh Abdoel Moeis sebagai subjek penelitian untuk mengungkap ideologi kolonialisme tersebut yang masih tersembunyi. Faruk (2009: 42) menyampaikan bahwa Abdoel Moeis terlibat dalam penulisan buku-buku Balai Pustaka dengan imbaan finansial yang tinggi.

Yang keempat dan kelima adalah novel Katak Hendak Jadi Lembu dan Hulubalang Raja. Novel ini memiliki kedudukan yang penting karena mengungkap kolonialisme di Aceh pada abad ke-17 dan dua novel ini juga dikarang oleh pengarang yang memiliki posisi yang penting bagi Balai Pustaka pada masanya, yakni 1908-1942. Novel itu dikarang oleh Nur Sutan Iskandar. Sarwadi (2004: 33) menyampaikan bahwa Nur Sutan Iskandar tercatat sebagai pengarang yang paling produktif pada masanya. Dua novel tersebut dipandang sebagai novel terbaik (Teeuw dalam Sarwadi, 2004: 36) dan Sarwadi (2004: 35).

\section{Alasan berkenaan terangkatnya per- budakan, terutama penindasan budak dan resistensi budak. Anatona} menyampaikan bahwa perbudakan di Indonesia sangat marak terjadi ketika masa kolonialisme, tetapi perbudakan dan masalah-masalah yang melingkupinya belum banyak yang meneliti (2000:4). Secara hakiki, manusia pada awalnya dilahirkan tidak membawa status sosial apapun, apalagi membawa identitas sebagai budak. Seseorang atau sekelompok orang diberikan identitas sebagai budak menandakan bahwa ada superioritas dibalik pemberian identitas itu. Superioritas Superioritas (Barat) menciptakan inferioritas (Timur). Anggapan inferior ini menjadikan manusia yang satu menindas manusia yang lain. Hal ini memunculkan masalah bagi kemanusiaan itu sendiri.

Alasan yang terakhir. Poskolonial sebagai sebuah teori yang membongkar wacana kolonial di daerah-daerah koloni, seperti Indonesia. Dengan demikian, teori ini dapat digunakan untuk membongkar wacana-wacana Barat yang masih tertinggal dalam novel tersebut. Bagaimana Barat $^{4}$ melihat Timur, dalam hal ini budak sekaligus perlakuan-perlakuan yang diberikan kepada budak itu sendiri.

Artikel ini mengemukakan dua hal penting. Pertama, Orientalisme kolonial dalam novel-novel Balai Pustaka (19081942). Kedua, Resistensi pribumi terhadap kolonial dalam novel-novel Balai Pustaka (1908-1942).

Teori poskolonialisme pada awalnya dimulai ketika adanya kesusastraan persemakmuran (common wealth) yang mencoba mengkaji mengenai efek dari kolonisasi yang dilakukan oleh Inggris. Pada perkembangan selanjutnya, sebuah tulisan dari Edward Said yang berjudul Orientalism yang mengangkat wacana-wacana kolonial yang sangat menghegemoni dunia Timur. Dalam pandangan Said (1978: 5), keberadaan Timur bukan begitu saja didapatkan sebagai Timur, tetapi Timur memang ditimurkan oleh Barat melalui pengetahuan-pengetahuannya. Timur disistematisasi dan dikuasai seluruh "tubuhnya" oleh Barat. Ide Edward Said berawal dari konsep discourse dari Foucault sebagai gurunya. Pandangan Foucault yang memandang bahwa kekuasaan menciptakan kebenaran-kebenaran dari discourse atau wacana yang dibuatnya (oleh penguasa) untuk menguasai atau menghegemoni kelas inferior.

\footnotetext{
${ }^{4}$ Barat dan Timur adalah istilah yang mengacu pada penjajah kolonial (Barat) dan daerah yang ditaklukkannya (Timur). Akan tetapi, istilah itu sudah mengalami perluasan, bukan saja menyangkut kolonial Eropa abad ke-16, melainkan juga mengacu kepada sebuah rezim atau kelompok atau individu yang masih memperlihatkan perlakuan-perlakuan kolonial Eropa masa silam. Sedangkan Timur, mengacu kepada kelompok masyarakat atau individu yang terhegemoni, termarjinalisasi oleh rezim atau kelompok atau individu yang mengakui dirinya memiliki kekuasaan lebih tinggi.
}

Jurnal IImu Sosial dan Humaniora| 252 
Orientalisme merupakan suatu cara untuk memahami dunia Timur berdasarkan tempatnya yang khusus dalam pengalaman manusia Barat Eropa, Timur bukan hanya dekat; ia juga merupakan tempat-tempat koloni-koloni Eropa yang terbesar, terkaya, dan tertua, sumber peradaban-peradaban dan bahasa-bahasanya, saingan budayanya, dan salah satu imajinya yang paling dalam dan paling sering muncul tentang "dunia yang lain" (Said, 1978: 1). Timur telah membantu mendefinisikan Eropa (Barat) sebagai imaji, idea, kepribadian dan pengalaman yang berlawanan dengannya.

Sebagai sebuah wacana tandingan, poskolonialisme melakukan resistensi terhadap hegemoni Eropa atau dominasi imperialis.

Selain bersifat radikal, Ashcroft (2001: 20) mengatakan bahwa resistensi itu juga bersifat pasif. Pada masyarakat poskolonial, resistensi sebagai perwujudan dirinya untuk menolak, yakni sebuah resistensi yang menggunakan cara lain dengan pemertahanan identitas dan kepemilikan budaya. Perlawanan/oposisi sering menjerat dalam wacana imperial untuk menaklukkan subjek jajahannya. Kontrol kolonial sangat kuat mengikat kaum terjajah. Pada dasarnya semua wacana kolonial selalu ada dalam oposisi biner, yakni penjajah/terjajah, beradab/biadab, putih/hitam dalam usaha melaksanakan cita-citanya untuk melakukan eskploitassi ekonomi secara politis (Ashcroft, 2001:21).

\section{PEMBAHASAN}

\section{ORIENTALISME DALAM NOVEL} BALAI PUSTAKA

Orientalisme dalam pandangan Edward Said merupakan paham yang dibentuk oleh Barat atau kelas superior terhadap Timur. Timur merupakan negara bentukan yang mereka ciptakan atau civilisasi agar menjadi beradab sebagai mana dirinya. Hubungan antara Timur dan Barat adalah hubungan kekuatan, dominasi, hubungan berbagai derajat hegemoni yang kompleks. Timur ditimurkan tidak hanya karena ia didapati dalam keadaan "bersifat Timur" dalam semua hal yang dipandang umum oleh ratarata yakni mudah untuk -dijadikan Timur. Orientalisme bukanlah fantasi kosong orang Eropa mengenai dunia Timur, melainkan suatu sosok teori dan praktek yang sengaja diciptakan. Ada hegemoni gagasan-gagasan Eropa mengenai dunia Timur yang mengulangi pernyataan mengenai keunggulan Eropa atas keterbelakangan Timur. Realitas Timur adalah berbeda dengan realitas Barat; kebiasaannya, warna kulitnya yang eksotik, dan kenangan dan pengalaman yang indah. Timur harus dipahami memiliki keterbatasan dan kelemahan sehingga membutuhkan kekuatan dan pengetahuan Barat. Oleh karena itu, Timur siap untuk diatur kembali, diperintah, dikuasai, dan direkonstruksi.

Dalam novel Siti Nurbaya, kolonial mencitrakan tokoh Datuk Maringgih sebagai tokoh yang serba buruk.

"Badannya kurus tinggi, punggungnya bungkuk udang, dadanya cekung, serta kakinya pengkar, kepalanya besar, tetapi tipis di muka, serta sulah pula. Rambutnya yang tinggal sedikit sekeliling kepalanya itu, telah putih sebagai kapas dibusur. Misal dan janggutnya panjang, tetapi hanya beberapa helai saja. Giginya hitam dan kotor, yang di muka keluar sebagai gigi tupai. Telinganya besar, seperti telinga gajah, kulit mukanya berkarut-marut dan penuh dengan bekas cacar (Rusli, 84).

Dalam novel itu, kolonial Belnda juga menggambarkan Datuk Meringgih sebagai tokoh yang sangat kikir dan penuh dengan pehitungan.

"dicekiknya lehernya, diikatnya perutnya, ditahannya nafsunya, asal jangan keluar uangnya. Jika ia makan nasi, hanya dengan sambal lada atau ikan kering saja yang disimpannya sampai beberapa hari. Lauk pauk ini padalah baginya, karena sangkanya dapur yang berasap setiap hari, tiada berguna dan banyak mengeluarkan biaya. Rumahnya sebagai kandang kambing dan pakaiannya yang seperti pakaian kuli itu, 
tiada mengapa baginya, asal jangan keluar duitnya, untuk sekaliannya itu. (Rusli, 84).

Kontruksi lain yang sengaja dibentuk oleh kolonial Belanda kepada para pribumi tampak pada upaya untuk mewajibkan para pribumi membayar belasting atau pajak hasil bumi. Para kolonial mengumpulkan para pribumi untuk mewujudkan upaya-upaya itu. "inilah maksud kami meminta datang Tuanku sekalian kemari supaya disampaikan pemerintah ini kepada anak negeri, dengan diterangkan apa sebabnya dan apa gunanya uang belasting itu. Mengertilah benarlah hendaknya mereka tentang perkara ini, supaya jangan sampai mereka berpikir, uang itu diminta sekedar hendak memenuhi kantung orang Belanda. Sekalikali negeri tiada beroleh hasil dari belasting ini, melainkan kita yang di sini jugalah.

Para kolonial sengaja menciptakan janji-janji yang sangat indah dan meyakinkan. Dalam hal ini, kolonial Belanda berkeinginan untuk menciptakan citra sebagai bangsa yang mengayomi Timur padahal menurut Aschroft Barat bersembunyi dibalik bangsa Timur dalam upaya mencapai cita-citanya.

"Lagi pula janganlah salah sangka. Sekalian kami bangsa Belanda yang ada di sini, ialah pegawai Gubernemen, sebagai TuanTuanku juga, dan Gubernemen itu bukanlah bangs Belanda atau kerajaan Belanda, sekali-sekali tidak lain melainkan penduduk tanah Hindia inilah. Bangsa Belanda di sini sekadar memerintah, menolong mengatur" (Rusli, 248).

Sementara itu, orientalisme dalam novel Salah Asoehan lebih diperlihatkan oleh perilaku Corrie du bussie dan Hanafi. Berikut adalah bebeapa data tentang orientalisme yang ada pada Salah Asoehan karangan Abdoel Moeis.

"Aku tahu betul bahwa aku ini hanyalah Bumiputera sadja, Corrie! Djanganlah kau ulang-ulang djuga." (Moeis, 7).
"Timur tinggal Timur, Barat tinggal Barat, dan tidaklah keduanja akan mendjadi satu" (Moeis, 26).

Pandangan inferior lain dari bangsa kolonial Belanda kepada masyarakat pribumi tampak pada novel Pertemuan Jodoh karangan Abdoel Moeis. Pandangan yang menggambarkan bahwa pribumi inferior tampak pada perilaku kolonial Belanda yang menuduh Ratna, pembantunya, sebagai pencuri perhiasan Nyonya Kornel. Dalam novel Pertemuan Jodoh, dikisahkan bahwa Ratna menjadi pembantu rumah tangga di rumah Nyonya Kornel. la dituduh mencuri perhiasan majikannya, padahal Ratna tidak mencurinya. Dalam konteks ini, pribumi yang direpresentasikan oleh Ratna dipandang kurang memiliki moral karena melakukan pencurian di rumah majikannya.

\section{RESISTENSI NOVEL-NOVEL BALAI PUSTAKA}

Ashcroft menyampaikan bahwa perlawanan seperti itu dapat dikatakan bersifat radikal. Resistensi radikal merupakan perlawanan masyarakat terjajah terhadap kekuasaan kolonial. Resistensi radikal dicirikan oleh adanya rencana-rencana pergerakan yang terorganisasi, yang dilakukan dengan menyerang secara langsung melalui peperangan atau dengan memproduksi teks atau bacaan ( Lo and Gilbert, 1998: 12).

Selain bersifat radikal, Ashcroft (2001: 20) mengatakan bahwa resistensi itu juga bersifat pasif. Pada masyarakat poskolonial, resistensi sebagai perwujudan dirinya untuk menolak, yakni sebuah resistensi yang menggunakan cara lain dengan pemertahanan identitas dan kepemilikan budaya. Perlawanan/oposisi sering menjerat dalam wacana imperial untuk menaklukkan subjek jajahannya. Kontrol kolonial sangat kuat mengikat kaum terjajah. Pada dasarnya semua wacana kolonial selalu ada dalam oposisi biner, yakni penjajah/terjajah, beradab/biadab, putih/hitam dalam usaha melaksanakan cita-citanya untuk melakukan eskploitassi ekonomi secara politis(Ashcroft, 2001:21). 
"Nurbaya lalu berdiri dan menolakkan Ludi, sambil berkata dalam bahasa Belanda, "Jika berani engkau mengganggu aku sekali lagi, kuadukanlah kelakuanmu yang tiada senonoh ini kepada kapitan kapal. Akan menyusahkan penumpanglah kerjamu di sni? Atau kausangka aku ini seorang perempuan jahat? Buka matamu, lihat terang-terang; jangan samakan saja orang baik-baik dengan orang jahat! Nyah engkau dari sini!" (Rusli, 178).

"Orang Belanda sudah lupa pula, bahwa kami bukan orang takluk, yang harus membayar upeti kepada bangsa Belanda. Negeri kami tiada diambil dengan asap bedil, oleh orang belanda, melainkan perjanjian" (Rusli, 249)

"Memang kemauan orang Belanda, kita anak negeri, miskin dan bodoh hendaknya, supaya mudah dipermain-mainkannya dan bila kita tiada berdaya lagi kelak, tentulah akan dijualnya seperti budak" (Rusli, 251).

Sementara itu, pada novel Pertemuan Jodoh, resistensi dilakukan oleh Ratna, seorang pembantu rumah tangga. Ratna dituduh mencuru di rumah majikannya, padahal ia sama sekali tidak pernah melakukannya. Karena dipandang sebagai pencuri kalung emas milik majikannya, ia dilaporkan ke polisi. Ratna tidak terima dengan perlakukan majikannya yang seorang Belanda itu. Akhirnya, ia melarikan diri dengan menceburkan dirinya ke sungai. Dalam konteks ini, Ratna sebagai pribumi melakukan perlawanan secara frontal.

Perlawanan yang dilakukan oleh Ratna akhirnya dapat membebaskan dirinya dari belenggu penjajah, majikannya. la akhirnya bertemua dengan tunangannya bernama Dokter Suparta dan ia menikah dengan lelaki itu.

\section{SIMPULAN}

Berdasarkan pembahasan, ada beberapa butir simpulan yang dapat dibuat.

(1) Orientalisme kolonial sangat tampak pada perilakunya kepada pribumi. Kolonial memandang pribumi sebagai masyarakat yang inferior dan sangat bergantung kepada dirinya (kolonial). Dalam konteks itu, kolonialisme Belanda memandang bahwa pribumi sangat perlu diberadabkan agar seperti dirinya. Mereka melakukan sivilisasi agar pribumi sama dengan dirinya. Oleh karena itu, Hanafi dalam Salah Asuhan, Untung Surapati dalam Novel Surapati, Suria dalam Novel Katak Hendak Jadi Lembu menunjukkan perilaku yang mengikuti budaya-budaya kolonial Belanda (Barat). Pemunculan peristiwa-peristiwa mengikuti budaya-budaya kolonial menunjukkan bahwa budaya Timur lebih buruk jika dibandingkan dengan budaya Barat (kolonial Belanda). Dengan demikian, Timur harus mengikuti Barat. Artinya, Timur lebih inferior daripada Barat.

(2) Resistensi muncul pada diri pribumi sebagai bentuk perlawanan karena sudah diperbudak oleh kolonial Belanda. Resistensi yang dilakukannya dalam bentuk memperjuangkan hak-hak mereka. Resistensi yang dilakukan oleh pribumi berupa resistensi pasif dan resistensi radikal. Resistensi pasif dilakukan dalam bentuk menirukan budaya kolonial tetapi sesungguhnya bertujuan untuk melawan mereka. Resistensi radikal dilakukan dengan cara melakukan perlawanan secara frontal kepada kolonial Belanda.

\section{DAFTAR PUSTAKA}

Ashcroft, Bill. 2001. Postcolonial Transformation. London and New York: Routledge Tyalor \& Francis

Fasseur, Cess. 1994. Cornerstone and Stumbling block Racial Classification and the late colonial state in Indonesia. Ed. Robert Cribb. Dalam The Late Colonial state in Indonesia, Political, and Economic Foundation of the Nederlands Indies 1880-1942. Leiden: KITVL Press.

Gilbert, Helen dan Jacqueline Lo. 1998. "Postcoloniality and The Question of Modern Indonesian Literature". An International Reasearch Worksop, 
The Rex Cramphorn Studio Centre for Performance Studies University of Sydney, Maret, 29-31.

Lasang, Nio., dkk.. 1983/1984. Sejarah Perlawanan terhadap Imperalisme dan Kolonialisme di Daerah Sulawesi Tenggara. Depdikbuddir Sejarah dan Nilai Tradisonal Proyek Inventarisasi dan Dokumentasi Sejarah Nasional.

Marsden, William. 1999. Sejarah Sumatera. (Penerjemah A.S. Nassution dan Mahyuddin Mendim. Judul Asli History of Sumatra diterbitkan oleh Black Horse Court di London). Bandung: Remaja Rosdakarya.

Neiboer, H.J. 1910. Slavery as an Industrial System: The Hague: Martinus Nijhoff.

Said, Edward W. 1978. Orientalism. London and Henley: Routledge and Kegan Paul.

Wertheim, W.F. 1999. Masyarakat Indonesia dalam Transisi: Studi Perubahan Sosial (Penerjemah Mishbah Zilfa Elizabeth. Judul Asli Indonesian Society in Transition: A Study of Social Change. Bandung: $W$. van Hoeve Itd-The Hougue). Yogyakarta: Tiara Wacana.

Christanty, Linda. 1994. "Nyai dan Masyarakat Kolonial Hindia Belanda". Prisma 10, Oktober.

Herawati, Yudianti. 2010. "Pemanfaatan Sastra Lokal dalam Pengajaran
Sastra". Jurnal Lingua Didaktika, Jurnal Bahasa dann Pembelajaran Bahasa, Volume 3, Nomor 2, Juli. ISSN 1979-0547.

Ronidin. 2010. "Masyarakat Minangkabau Pasca-PRRI: Dalam cerpen Ketika Jendral Pulang Karya Khairul Jasmi”. Jurnal Lingua Didaktika, Jurnal Bahasa dan Pembelajaran Bahasa, Nomor 3, Volume 2, Juli. ISSN 19790547.

Yasa, I Nyoman. 2010. "Tesis, Antitesis, dan Sintesis Eksistensi Kembar Buncing dalam Novel Incest Karya I Wayan Artika". Jurnal Prasi, Vol. 6, No. 11, Januari-Juni, 2010. ISSN 1693-6124

Mahayana, Maman S. 1994. Politik Kolonial Belanda di Balik Pendirian Balai Pustaka. Universitas Indonesia. Laporan Penelitian Tidak Diterbitkan.

Prasaja, Y.B. Agung. 1998. Fenomena Sikap Mental Imperialisme Baru dalam Sastra Pascakolonial Kenya Berbahasa Inggris: Kajian terhadap Novel $A$ Grain of wheat dan Weep Not, Child karya Ngugi Wa thiong'O. Tesis UI Tidak Diterbitkan.

Razif. 2005. "Bacaan Liar" Budaya dan Politik Pergerakan pada Zaman Pergerakan. Edi Cahyono's Experien. http://www.gecities.com. Diunduh tanggal 26 Agustus 2009. 